\title{
Quality Medical Service for Quality Assurance in Neurosciences and Medical Sciences Using International Standard Organization, Quality Standards and Concepts of Total Quality management (TQM)
}

\section{Upadhyay $P^{1 *}$, Tiwary $G^{2}$ and Pant $I^{3}$}

${ }^{1}$ Head of Neurosurgery Department, Institute of Human Behaviour and Allied

Sciences, Delhi, India

${ }^{2}$ Head of Pathology, House of Diagnostic (HOD), Delhi, India

${ }^{3}$ Assistant Professor Neuro-Pathology, Institute of Human Behaviour and Allied

Sciences, Delhi, India

*Corresponding Author: Upadhyay PK, Head of Neurosurgery Department, Institute of Human Behaviour and Allied Sciences, Delhi, India.
Received: September 12, 2020

Published: November 19, 2020

(C) All rights are reserved by Upadhyay PK., et al.

\begin{abstract}
Non-standardization of services and lack of quality services with special operating procedures are main culprits for non-delivery of quality medical service which lead to less patient satisfaction leading to multiple patient - doctor relationship, legal and compensation cases. In this study we concentrated on the improvement of quality health and medical care services (QMS) using International Standard Organization (ISO) standards and application of total quality management (TQM) in health and medical care services so that a proper level of quality service may be assured(quality assurance) using bench marking with highest level in the field. Thereby patient satisfaction is also increased leading to lesser conflict and better earning of the healthcare system. This may thus save time and finance which can be utilized for further enhancement of medical and health services to upgrade to match best in the field and can be used as bench marking for other health care services.
\end{abstract}

Keywords: Quality Assurance; Standards; ISO; TQM; Medical; Neurosciences

\section{Introduction}

There are two convention of quality in world history as stated by Ellis and Whittington. These are Quality in Industry and quality in Health care. With widespread use of Total quality management (TQM) and continuous quality improvement (CQI) health was going along Industrial type of quality improvement [1].

Past trends of quality in health sector. There is no clear time when quality started in health care but it appears to be as old as mankind itself.

Present concept of quality management in health care started in 1918 with American college of surgeons started hospital stan- dardization program by providing criteria and standards for accreditation of the hospitals.

The joint commission on accreditation of hospitals (JCAH) started in 1952 and published standards and was made mandatory for all hospital to follow and comply for accreditation with JCAH.

ISO (international standard organization) was started in 1947 in industry sector to facilitate international coordination and understanding.

In 1966 Government of USA started regulatory authority to regulate health care quality. 
Management Guru Edward Deming introduced the concept of Total quality management (TQM) which was also applied to healthcare systems. This is a continuous effort by all health care management people to the requirement, expectation to satisfy the end user, the patients.

In early 1990s, there was an increasing concern for quality in health care and thus started the quality movement in health care.

\section{Materials and Methods}

The Universal Declaration of human right, adopted by the United Nations (UN) in 1948, proclaimed that "everyone has the right to a standard of living, adequate for health and well-being of oneself and one's family including food, clothing, housing and medical care". These too have to have some quality.

\section{What is quality?}

Quality is one of very important concept in Neurosurgical and surgical delivery systems. Like other medical fields quality concepts were brought intentionally in neurosurgical and surgical field as well. Survival of fittest is the dictum of the all-time [2].

Quality is Degree of excellence achieved in the given field as perceived by the service provider. It means adherence to the already determined features in rendered services which patient gets every time when he/she visits hospital service [1].

The International Organization for standardization (ISO) defines quality as "the totality of features and characteristically of the service that bear on its ability to satisfy the stated and implied need of the patients".

Therefore, it's the totality of services or its combined effect on the consumer which matters as quality and the total ability of services to satisfy the need of patient by curing of disease and causative factors to restore the health to normal leading to satisfaction of patient and patient's attendant [3]:

- According to Philip B Crossby, Quality is the conformance to requirement of the given specification.

- According to Joseph M Juran Quality is the fitness for use.

- $\quad$ According to Armand V Feigenbaum Quality is what consumer say it is.

\section{Standards $[4]$}

A statement of expectation that defines the structure and process that must be substantially in place in an organization to enhance the quality of Neurosurgical and surgical care. Quality

The degree of adherence to pre-established criteria or standards.

Quality assurance [4]

Part of quality management focused on providing confidence that quality requirements will be fulfilled.

\section{Quality improvement}

Ongoing response to quality assessment data about a service in ways that improve the process by which are provided to Neurosurgical and other surgical consumers/patients.

\section{Benchmarking [5]}

It is a process of comparing a hospital performance against that of organizations that have been identified as excellent. There are three types of benchmarking [6]:

- Internal benchmarking: It compares performance between functional areas of departments within an organization. For examples infection rate in department of Neuro- surgery, surgery and department of paediatric surgery.

- Competitive benchmarking: Used to close the gap between organization performances with that of its industry competitors. It is also called performance bench marking. For example, infection rate in department of neurosurgery of one hospital with that of other standard hospital with best result.

- $\quad$ Comparative benchmarking exercises examining a process in another industry to apply the principles that makes it effective to a similar process. For example, success rate in hospital industry with any other successful industry.

\section{Results and Discussion}

In the start of quality improvement preparations involves several steps using a number of different quality tools. Eight quality tools are available to help organization to better identify and improve their processes. The essential tools for the discovery tools to identify and improve are described below.

After world war two Japanese adopted 'quality' as the philosophy for economic recovery. They sought seven tools to accomplish the economic recovery. 
Each is described below [7]

Flow chart

Flow chart gives visual illustration of the sequence of the Operations needed to complete task. Every process is put to, till finish the job.

\section{Cause and effect diagram (Fish bone/Ishikawa charts)}

- Cause and effect diagram also known as fishbone diagram helps to obtain more information about process and its output. It will help to find out root cause.

- In 1943 Kaoru Ishikawa developed the cause and effect diagram at the University of Tokyo.

- This diagram has two sides on right side is the list of effect which lists the problem or the quality concern. On left side is the cause side, it list the primary cause of the problems.

Parito - charts (80:20 charts)

- $\quad$ Parieto charts is used to priorities the problems (P for P), to decide what problems should be addressed.

- It was devised by Vilfred Parieto in1906 in Italy.

- No organization will have enough resource to handle every problem so they should priorities them. That is the "important few and trivial many".

- So, to priorities the problem finds out its causes and try to correct them first and then proceed on.

\section{Check- sheet}

Check sheet will allow user to collect data directly from process and put them as tables which makes it easy, systematic and organized manner which shows the history and pattern of variation.

At the beginning, in change of process, this tool is used to recognize the problems and collect the data easily.

There could be:

- $\quad$ Defective item check sheet.

- Defective location check sheet.

- Defective cause check sheet.

- $\quad$ Check-up confirmation check sheet.

\section{Control charts}

- The Control charts was developed in mid-1920 by Walter Shewhart of Bell Labs.
- Control charts are used to make sure that the process is in control.

- It is also used to monitor and control the process variations on a continuous basis.it also allows the user to take proper corrective actions to eliminate the sources of variations.

- This tool has become a main contributor to the quality improvement process.

\section{Histogram}

Histogram is the tool used for summarizing analyzing and displaying the data. It gives the user a graphical representation of the amount of variation found in the set of data. Histogram shows a visual summary of data, which will be simple to understand. This tool is used when the data given is of various verities and is difficult to understand.

Histogram could be of five types

- Bell shaped.

- Double peak type.

- Plateau distribution.

- Comb type distribution.

- $\quad$ Skewed Distribution.

\section{Scattered diagram}

Scattered diagram is used to recognize the correlation which might exist between the quality characteristic and the factor which might be driving it. A scattered diagram is the nonmathematical or graphical approach for recognizing relationship between the performance measure and the factors which might be driving it. The scattered diagram is used when there is assumed variation of two item, connected in some way.

\section{Brain storming}

- In this all concerned people sit together and discuss the pros and cons and ultimately arrive at solution to the problem. Finally, brain storming is done with stakeholder concerned to find out reason of problems and ways to improve quality of service to increase patient satisfaction or clients.

- $\quad$ ISO is a Quality management system (QMS) in healthcare Institutions.

- Quality management system is a collection of policies, plans, practices and the necessary infrastructure by which an organization can work towards minimizing and eventually elimi- 
nating the non-conformity to specifications standard and patient's expectation in a cost effective and efficient manner.

- $\quad$ Such system may be ISO 9001:2000 and National accreditation board for hospitals and healthcare providers (NABH) accreditation procedure, JCI etc.

- ISO 9000 is asset of standards that describe and define the minimum requirement of a "quality management system" require to make sure that an organization's product or services meet the/or exceed the consumer needs and expectation.

- $\quad$ ISO 9000 help in meeting consumer's needs. It helps to gain self-confidence, to attain the competitiveness in both national and international markets and acts as a blueprint for efforts to enhance a quality system of an organization.

- Certification is done when an accredited third party visits an organization, assesses their management system and issues the certificate to show that the organization will abide by the principles set out in their standard which are in consonance to best practices in health care industry.

- International Organization for Standardization (ISO) is a network of national standard institute of 157 countries worldwide.

- ISO 9000 is the most commonly used international standard that gives a framework for an effective quality management system.

- ISO 9000 family of standards usually deals with quality management and IS09001:2000 is applicable to all healthcare organizations.

- ISO 9001 series of standards consists of ISO 9000 (Fundamental and vocabulary) - It introduces a user to the concepts behind the management systems and mentions the terminology used.

- IS09001 (Requirements) It sets out the criteria required to operate according to the standard and obtain certification.

- ISO 9004 (Guidelines for performance improvement) - It is based on eight quality management principles, which are designated to be used by senior management as a framework to guide the organization towards improving performance by considering the requirements of the interested parties and not just consumers.

- ISO 9001 is suitable for organizations looking to improve the way it is operated and managed irrespective of the organization that are prepared to implement it throughout their orga- nization rather than at particular sites, department or divisions.

- $\quad$ The structure of ISO 9000:2000 has 8 causes.

The main benefits of ISO certification are

ISO 9000:2000 is widely accepted as system of quality management and more than half a million organization re imparting the ISO standards which acts as a framework for quality management.

This gives a sentiment of satisfaction among the user and the patients that a form of good quality assurance is in place which increases the acceptability of the institutions.

The benefits of implementing ISO 9001 as a quality management system in hospitals are multiple.

Thus, the benefits of ISO 9000:2000 may be as below:

- It helps an organization to clarify aims and objectives and framing the policies for most efficient achievement.

- $\quad$ Organization can analyse and understand its strength, weakness, threat and opportunity using SWOT analysis.

- Help develop proper processes and activities to develop the best practices.

- Minimizes the cost, reduces wastages, promote optimum utilization of resources and hence reducing cost of care.

- Improves employee's understanding, of roles and responsibilities within the quality management system of organization.

- $\quad$ Alignment and integration of individual and departmental objectives with the aim and objectives of the organization.

- Recognize and addresses systemic breakdown within the organization.

- Ensures the conformance to effectiveness of documented processes.

- $\quad$ Focuses on patient care, satisfaction and safety. Minimizes the chance of errors and compliance to documented standards.

- Improvement in reputation of hospital. The improvement in quality of service increases patient confidence and satisfaction and thus strengthening the relationship with hospital.

- Improvement in quality of documents and records. 
- $\quad$ Also serves as foundation for ongoing improvement initiatives.

- $\quad$ Facilitates recognition and accreditation by other regulatory authorities.

- Eliminates ambiguity as to who is to do what, how, when and in what manner.

\section{ISO 9001 in health care [8]}

International standard organization (ISO) means "equal at all sites". Till date more than half a million organizations in 161 countries have implemented the ISO standard.

In 1987 ISO 9000 standard was published. The standard underwent revision in 1994, 2000, 2008 and the last revision was in the year 2015.

Normally ISO revision is done in every five years. Last revision done in 2015 (IS09001:2015) applies to any organization, regardless of size or industry. It helps them:

- Organize process

- Improve the efficiency of processes.

- Continuity to improve.

All organization that uses ISO 9001 are encouraged to transition to ISO 9001: 2015 as soon as possible.

As of September 14, 2018, organizations that are currently registered to ISO9001:2008 should have transitioned to the 2015 standard.

All the requirements of ISO 9001:2015 are generic and are intended to be applicable to any organization, regardless of its type or size, or the products and services it provides, are generic and are intended to be applicable to any organization, regardless of its type or size, or the products and services it provides.

Changes introduced in the 2015 ISO 9001 continues to adapt to the changing environment in which organization operates. Some of the key updates in ISO 9001:20015 includes:

- The introduction of new terminology.

- Restructuring some of information.

- An emphasis on risk-based thinking to enhance the application of the process approach.

- Improved applicability for services.
Increased leadership requirements

- $\quad$ The total quality management (TQM) [9] in health care is a philosophy that focuses on "customer satisfaction" and "organizations' objectives" for long term success of the health care organization.

- Total quality management (TQM) in health care is based on the involvement of "all the employees" of an organization in improving the processes, products, services and the culture in which they work.

- Total quality management (TQM) in health care is based on "continuous improvement" of all operations, processes and functions. Total quality Management (TQM) in health care is used interchangeably with "continuous quality improvement" (CQI) in many areas

- Total quality management (TQM) in health care is achieved by understanding, meeting and exceeding the needs of the consumer.

- In six sigma the aim is "no flaw or $<3.4 /$ million in process/ product defect while in Lean management the value of product or service is increased by perfecting the process and cycle time is deceased for saving and aim should be to have Zero waste.

- In total quality management (TQM) in health care begins with simple idea and a supposition that everything can be constantly improved/enhanced. TQM is a philosophy as well as a set of a continuously improving organization.

TQM integrates basic and fundamental management techniques, improvement efforts, futuristic quality plans, innovations and their successful implementations. Total quality Management (TQM), in health care like in many countries, has been adopted from industrial experience. But its application in health care requires variation as the health care organizations as it is different than industries as such, on many accounts like:

- Its closer connection to politics.

- Its multifaceted organizational structure.

- Its intrinsic character.

- Its objectives are continuously shifting.

- Value and work ethics of the health care providers.

Considering above differences is crucial to the successful implementation and development of a TQM system in health care. Therefor the same TQM as applicable to industry cannot be directly placed in health care organization/industry.

Citation: Upadhyay PK., et al. "Quality Medical Service for Quality Assurance in Neurosciences and Medical Sciences Using International Standard Organization, Quality Standards and Concepts of Total Quality management (TQM)”. Acta Scientific Medical Sciences 4.12 (2020): 44-52. 
The quality professionals in healthcare to define principles, philosophies, and techniques that will decide the quality standards appropriate for their own medical industry.

Achieving the principles of TQM in a healthcare organization is challenging, as TQM is very complex when implemented through many processes and many areas of health care facility/industry.

\section{Deming's TQM philosophy}

Dr Deming is recognized with providing the foundation of the Japanese quality miracle. In 1986 he proposed 14 points for managing the improvement of quality, productivity, and competitive position.

They are as follows:

- Create steadiness/constancy of purpose for improvement of product and service.

- $\quad$ Adopt a value added (based) philosophy to deliver product and services.

- $\quad$ Cease independence on mass inspection. The habit of depending on scrutiny/inspection for improvement of quality should be avoided.

- $\quad$ End the practice of awarding business on the basis of price alone. Tender process on basis or lowest offer should not be done.

- It is essential to improve the system of service constantly (continuously) and forever.

- Institute training on the job.

- $\quad$ Adopt the institute leadership for supervising staff.

- Drive out fear.

- Break down barrier between staff and patients (by improving communication).

- $\quad$ Eliminates slogans, exhortations and targets for staff.

- Eliminate numerical quotas for staff and numerical goals for management.

- $\quad$ Satisfaction of patient clients in delivery of service. Eradicate barriers that robs people of pleasure in their work, and eliminates the annual rating or merit system.

- Encourage dynamic program for education and self - improvement for everyone.

- Take action to put everyone in the organization to work, to achieve and accomplish the transformation.

Ishikawa's philosophy of management

Kaoru Ishikawa is one of the leaders in philosophy of total quality management in Japan. He was a university Professor and influential quality management innovator best known in North America for the Ishikawa or cause and effect diagram (also known as Fishbone Diagram). He also developed the "quality circle" of 7-8 persons of different departments forming the group of people to discuss and improve and implement in quality processes.

\section{Cause and effect diagram (Fish bone/Ishikawa charts)}

Cause and effect diagram also known as fishbone diagram helps to obtain more information about process and its output. It will help to find out root cause.

In 1943 Kaoru Ishikawa developed the cause and effect diagram at the University of Tokyo. This diagram has two sides on right side is the list of effect which lists the problem or the quality concern. On left side is the cause side, it lists the primary cause of the problems.

Kaoru Ishikawa postulated 11 points philosophy of total quality management are as follows:

- Education is starting and ending point of quality.

- Knowing the requirement/need of consumer is the first step in quality.

- The ideal state of quality is when quality inspection can be avoided.

- $\quad$ Root cause (by Cause and effect analysis) and not the symptoms are to be removed.

- Quality control is the combined responsibility.

- Objectives are not to be confused with means (objectives are achieved through means).

- Quality with long term success should be given importance.

- The entrance and exit of quality is marketing.

- Facts should be presented before the subordinates in a proper manner.

- The seven tools of quality solve most of the problems in an organization.

The seven tools are

- Flow charts

- Cause and effect diagram (Fish bone/Ishikawa charts.

- $\quad$ Parito - charts. $(80: 20)$ charts.

- $\quad$ Check- sheet

- Control charts.

- Histogram.

- Scattered diagram. 
Data are considered false without dispersion (spread, scattering) information.

\section{JURAN'S management theory}

- $\quad$ One of the leaders of total quality management from Romania is Joseph M. Juran. The human dimension to the concept of quality is added by Juran, expanding it into the method now known as Total quality management (TQM).

- His well-known work includes Jurans Tri-ology which are three managerial processes that he identified for use in managing for quality: quality planning, quality control and quality improvement.

- Juran used/popularized Pareto principle in 1937.

Importance of TQM in health care [9]

- TQM in health care viewed "patient satisfaction" as one of the important dimensions. Quality is whether the service offers patient what they want. Professional quality refers to professional view of whether the service meets patients need as assessed by professional and whether personnel correctly select and carry out procedures which are believed to be necessary to meet patient's needs.

- In traditional quality assurance, efforts is to achieve local or national standard, however, in TQM steps are being taken to improve these principles, for example turn around for admission to a patient requires 30 minutes. The review may show that few minutes of delay is there in reaching to outpatient department room. The delay is curtailed by finding a shorter route. Further view it shows that registration took 5 minutes as it was done manually now this registration may be done by digital method to reduce time in a prefill format digitally. And so on and on, the aim is to decrease the time further and further so as to trouble of patient is decreased and satisfaction is achieved.

- $\quad$ Another concern in TQM is the number. If patient perceive that they are rushed through them, although one may achieve lesser time but will hamper patient satisfaction. Quality is more of a positive perception rather than number. In health care organization quality consists of doing right thing at right time.

\section{Requirements of TQM}

The requirement for application of TQM in the health care sector can be as follows:

- $\quad$ Top management Leadership.
- $\quad$ Measuring Patient Satisfaction.

- Team work.

- $\quad$ Training of staff/workers.

- Design Quality system (Process Management).

- $\quad$ Bench marking.

Requirements of TQM (Pre requisite of TQM)

- Leadership of top management: The two of the most important principles of total quality management are top management leadership and employee's empowerment which are assumed to have impact/relationship with patient satisfaction.

- Consumer satisfaction: Measuring consumer satisfaction is the main objective of any service organization in building up of Patients satisfaction amongst the consumers.

- Team work: A good quality team work is foundation of success in an organization. The most important quality of a good team is to have clear and same goals.

- $\quad$ Training of personnel: Proper training in achieving the goal for the organization is an essential component so that everyone contribute fruitfully in achieving the goal of the organization.

- Benchmarking: Business survival is increasingly difficult in the modern world. In order to survive, organisations need a commitment to excellence and a means of evaluation for the commitments the outcomes. Bench marking provides one way for doing this. Benchmarking can be considered as a performance improvement method that has been used for centuries. Recently it has been used in healthcare industry where it has the prospective of improving the efficacy, cost-effectiveness, and quality of healthcare services.

The regular method to gain success is as follows:

- Develop a plan.

- Select a good team.

- $\quad$ Select a model and follow the model.

- Gain management support.

- Implement improvement.

The five basic pillars of TQM are:

- Higher level of commitment for quality enhancement (improvement).

- $\quad$ Consumer oriented methods to build long term thrust worthy relationship.

Citation: Upadhyay PK., et al. "Quality Medical Service for Quality Assurance in Neurosciences and Medical Sciences Using International Standard Organization, Quality Standards and Concepts of Total Quality management (TQM)”. Acta Scientific Medical Sciences 4.12 (2020): 44-52. 
- $\quad$ Constant (continuing) improvement leading to persistent development by setting aims and objectives.

- Benchmarking with several precise tools and quality enhancing techniques.

- $\quad$ Strengthening the employee base by focusing at any stage of a process on quality, where lies the consumer satisfaction leading to continuous benefit to the organization.

\section{Results}

Application of some form of quality assurance and quality standard through quality medical services using various methods like ISO or philosophy of total quality management (TQM) increases reliability, gives assurance to receiver and also deceases the waste and increases patient satisfaction and ultimately improving the quality of health services.

The benefit of ISO 9001 quality management systems are:

- $\quad$ Process approach.

- $\quad$ Objectivity for the process management.

- $\quad$ Provides QMS framework.

- Allow incorporating best practices.

- Allow incorporating other management systems.

- $\quad$ Third party certifiable.

\section{Benefits of TQM (Total quality management)}

Reducing errors and doing things at right time, saves time and resources. These Savings, thus are utilized for expansion of services and used for benefits of employees finally leading to increase service quality. TQM builds up atmosphere of excitement and sense of accomplishment and appears as rewards to the effort so put in by all members of the team TQM.

Thus, any lacuna so found can also be plugged to achieve even higher goals by TQM. Viewing care from patient's point of view is an ethical and professional imperative. Thus consumer satisfaction also decreases the malpractice and propensity to litigation which in turn will benefit the organization in long term.

\section{Conclusion}

The deteriorating Doctors and patient relationship in $21^{\text {st }}$ century have many factors like of lack of transparency in management of patient, lack of communication and lack of trust between the parties involved. That can be termed as due to bad interpersonal relationship between health caregivers and the receivers. But more importantly the part played by substandard health services due to lack or non-implementation of quality medical services with proper quality assurance and standards leads to patient remaining unsatisfied and ultimately leading to development of some form of struggle which may be legal, financial and even physical struggle.

Therefore application of some form of quality assurance with quality standards safe guards against such problems. It also substantially improve the functioning of the health care system by increasing capability and capacity both. All in all, these increases the satisfaction level of patient and also increases faith of the patient and their attendants in the system and decreasing and finally aim to removing any form of struggle altogether. Thus a lot of man power hours and financial burden accruing to the health care institution is saved and same can be utilized for further improving the facilities and services.

Here we described the role of ISO (International standard organization) and TQM (total quality management to achieve the goals in health care services.

\section{Declaration}

The study has been conducted by the authors and no any financial help has been taken from any agency. There is no conflict of interest what so over.

\section{Bibliography}

1. Upadhyay PK and Tiwary G. "Concept of Quality services in Medical Science with special assurance to Super specialty surgical practice". Medical Science 11.41 (2014): 24-30

2. Tiwary G and Upadhyay PK. "Safe conduct of medical or surgical procedures including neurosurgical procedures and special operating procedures (SOP)". Medical Science 11.41 (2014): 31-36.

3. Upadhyay PK and Tiwary G. "Standard of operation theatres (OT)/Procedural rooms". Medical Science 1.41 (2014): 37-42.

4. P K Upadhyay., et al. "Quality assurance in neurosciences and suitable standards for Neurosurgical operation theatre and procedural rooms". Clinical Neuroscience and Neurological Research International Journal 1.1 (2018): 180002.

5. Text Book of Quality assurance and Standards in Neuro and medical sciences: Dr P.K. Upadhyay, Tiwary G, Kritika, Kartikeya; Smash world, Canada (2019). 
6. Text Book of Quality assurance and Standards in Neuro and medical sciences: Dr P.K. Upadhyay, Tiwary G, Kritika, Kartikeya; Smash world, Canada $2^{\text {nd }}$ edition (2020).

7. Text book of quality assurance and standards in Neurosurgery and surgical sciences: authors; Dr P K upadhyay, Dr G Tiwary (2020).

8. Using ISO 9001 Nin health care. ISO9001:2015 internal audits made easy and IS09001:2015 explained.

9. Total quality management: a comprehensive strategy towards the Implementation of effective and efficient healthcare delivery system in Africa by john Ngosong, Morfaw (2006).

\section{Assets from publication with us}

- Prompt Acknowledgement after receiving the article

- Thorough Double blinded peer review

- Rapid Publication

- Issue of Publication Certificate

- High visibility of your Published work

Website: www.actascientific.com/

Submit Article: www.actascientific.com/submission.php

Email us: editor@actascientific.com

Contact us: +919182824667 